\title{
Multiple Esophageal Hyperplastic Polyps in a Nigerian Woman
}

\author{
Abiodun Christopher Jemilohun ${ }^{1}$, Mustapha Akanji Ajani ${ }^{2}$, Tosin Samuel Ola ${ }^{1}$ \\ Departments of ${ }^{1}$ Medicine and ${ }^{2}$ Histopathology, Babcock University Teaching Hospital, Ilisan-Remo, Ogun State, Nigeria.
}

\section{Corresponding Author:}

Dr. Abiodun Christopher Jemilohun

Email: chrislohun2010@hotmail.com

This is an Open Access article distributed under the terms of the Creative Commons Attribution License (creativecommons.org licenses/by/3.0).

Received : April 6,2017

Accepted : July 1,2017

Published : July 30, 2017

\begin{abstract}
Background: Hyperplastic polyps of the esophagus are rare lesions that are often associated with reflux esophagitis and hiatal hernia. They are frequently asymptomatic and discovered incidentally at endoscopy or radioimaging. Case Report: We present a 25 -year-old female who had multiple nodules of the lower esophagus at endoscopy. Her major complaints were recurrent heartburn, regurgitation and epigastric pain. Sections of the biopsied esophageal nodules showed features that were consistent with hyperplastic polyp of the esophagus. Conclusion: Though the report of esophageal hyperplastic polyp from Nigeria is scarce in the literature, the rate of detection and reporting is likely to increase as gastrointestinal endoscopy services become more available and accessible in the country.
\end{abstract}

Keywords: Biopsy, Endoscopy, Esophagitis, Heartburn, Nigeria, Polyps.

\section{Introduction}

Benign esophageal tumors are an assorted group of disorders that are rare in comparison to malignant tumors or other benign conditions of the esophagus. They have a prevalence of less than $0.5 \%$ [1] and constitute less than $1 \%$ of all esophageal tumors [2]. They are often asymptomatic and discovered incidentally at endoscopy or radioimaging $[3,4]$. There are various ways of classifying benign esophageal tumors such as classification by histological cell type (epithelial and non-epithelial tumors); classification by location in the esophageal wall (intramural and extramural tumors); and classification by endoscopic appearance (flat, raised, or cystic lesions) [1,4-6].

Polypoid epithelial lesions of the esophagus are rare worldwide $[4,7,8]$. We encountered only a report of hyperplastic polyp of the esophagus from Nigeria in our literature review [9]. We here report a patient who presented with symptoms consistent with gastro-esophageal reflux disease (GERD) and dyspepsia in which we found multiple nodules in the lower esophageal mucosa at endoscopy and histological features consistent with hyperplastic polyps.

\section{Case Report}

A 25-year-old lady presented at the Emergency Room of our hospital because of a sudden onset of severe epigastric pain and two episodes of vomiting that started 30 minutes prior to her presentation. The symptoms started immediately after a meal. She had a 12-year-history of recurrent epigastric pain, heartburn and regurgitation. The symptoms were usually relieved by intake of antacids. The pain and heartburn sometimes woke her up at night. She had been avoiding certain foods because of her symptoms.

There was no history of hematemesis, melena or recurrent vomiting. She reported no history of difficulty swallowing or weight loss. She did not abuse non-steroidal anti-inflammatory drugs. She neither smoked cigarette nor consumed alcohol. The only significant finding on physical examination was marked epigastric tenderness. 
Upper gastrointestinal endoscopy showed multiple nodules of varying sizes with background mucosal hyperemia in the lower esophagus [Fig.1]. No ulcers or hiatal hernia was found. The gastric fundal mucosa was severely inflamed. The mucosae of the gastric body and antrum were moderately inflamed. There were no ulcers or mass lesions. The first and second parts of the duodenum were normal in appearance. Few esophageal nodules were biopsied. Multiple biopsies were also taken from the stomach.

Sections of the esophageal mucosal biopsy showed an overlying admixture of gastric foveolar epithelium and stratified squamous epithelium with focal areas of ulcerations. There was moderate infiltration of the lamina propria by neutrophil polymorphs, lymphocytes and plasma cells. Also seen were granulation tissue and edematous stroma. No focus of dysplasia or malignancy was seen [Fig.2,3]. These features are consistent with hyperplastic polyp of the esophagus.

Sections of the gastric corporal, incisura and antral mucosal biopsies showed moderate infiltration of lamina propria by neutrophil polymorphs, lymphocytes, and plasma cells. There were few colonies of Helicobacter pylori (H. pylori) like organisms within the glandular crypts and lumen. No focus of intestinal metaplasia, dysplasia or malignancy was seen. The overall picture was consistent with $H$. pylori associated chronic active gastritis.

The patient was treated with triple regimen for $H$. pylori infection and she is currently on proton pump inhibitor (PPI) therapy.

\section{Discussion}

The exact prevalence of esophageal hyperplastic polyp is not known but it is generally believed to be rare. Buyukasik et al. reviewed a total of 66 upper gastrointestinal polyps from 59 patients and found esophageal polyps to be less common as compared to gastric and duodenal polyps [29 in the

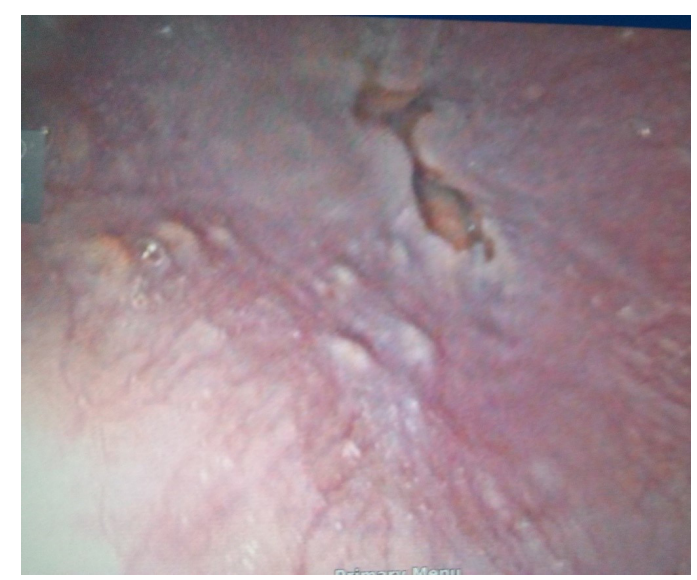

Fig.1: Multiple nodules of varying sizes with background mucosal hyperemia in the lower esophagus.

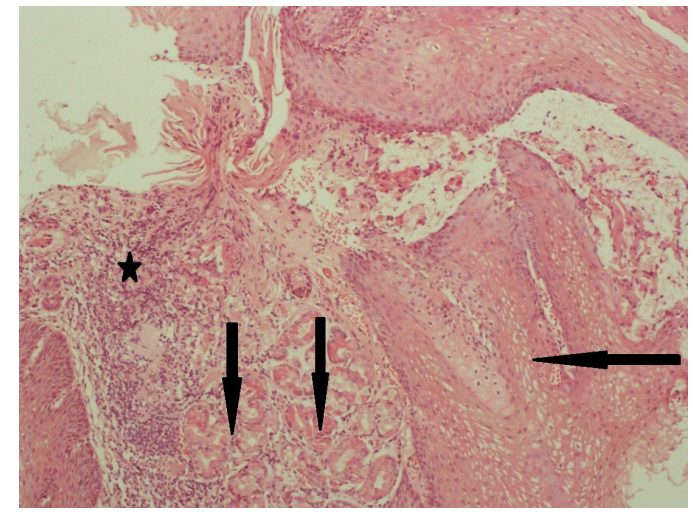

Fig.2: Photomicrograph of the esophageal mucosal biopsy showing admixtures of hyperplastic squamous epithelium (single arrow) and gastric foveolar epithelium (double arrows) with inflamed lamina propria (star). (Hematoxylin and eosin stains, $\times 100$ ). These features are consistent with esophageal hyperplastic polyp.

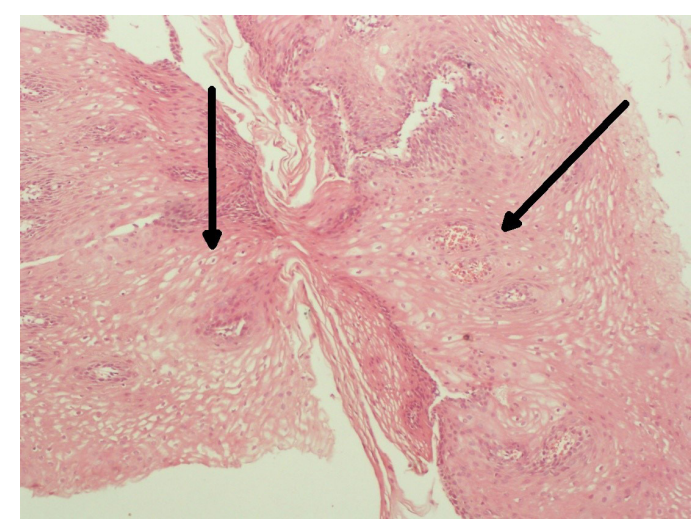

Fig.3: Photomicrograph of the esophageal mucosal biopsy showing overlying hyperplastic squamous epithelium (arrows). (Hematoxylin and eosin stains, $\times 100)$. 
antrum $(43.9 \%), 15$ in the corpus $(22.7 \%), 11$ in the cardia $(16.7 \%), 3$ in the fundus $(4.54 \%), 3$ in the second part of the duodenum (4.54\%), 2 in the duodenal bulb $(3.03 \%)$ and 3 in the lower end of the esophagus (4.54\%)] [7]. Tsai et al. found 148 benign esophageal lesions in a retrospective review of 2,997 endoscopic examinations, of which 18 $(12.16 \%)$ were hyperplastic polyps [5]. The benign esophageal lesions consisted of 129 (87.16\%) epithelial and 19 (12.84\%) sub-epithelial lesions. There were six types of epithelial lesions, of which hyperplastic polyp was the fourth commonest $(12.16 \%)$ [glycogenic acanthosis (66), heterotopic gastric mucosa (21), squamous papilloma (20), hyperplastic polyp (18), ectopic sebaceous gland (3) and xanthoma (1)] [5].

Hyperplastic polyps of the gastric corpus and antrum usually develop in association with chronic gastritis but the pathogenesis of esophageal hyperplastic polyps is still not fully understood [10,11]. However, there is evidence to suggest that the lesion develops as a result of mucosal regenerative response to surrounding mucosal injury $[5,6,8]$. The lesion is commonly associated with erosive esophagitis/or hiatal hernia [4-6,8,12,13]. Other potential etiologies include eosinophilic esophagitis, Crohn's disease, medication-induced esophagitis, infection, anastomotic or polypectomy sites, photodynamic therapy, and type 1 neurofibromatosis $[5,8,14,15]$.

Two studies that reported the frequency of association of esophageal hyperplastic polyps with Barrett's esophagus (BE) are conflicting $[8,11]$. While Abraham et al. reported 15\% (4 out of 27 patients) association [8], Long and Odze reported a 33\% (15 patients out of 46) association and suggested that the polyps may be a harbinger of $\mathrm{BE}$ because they were associated with either ultrashort $(<1 \mathrm{~cm})$ or short segment (1 to $3 \mathrm{~cm}) \mathrm{BE}$ [11].

Usually, esophageal hyperplastic polyps occur as solitary small sessile polypoid lesions but they could occur as multiple small sessile polypoid lesions. The lesions tend to vary from 5-20 $\mathrm{mm}$ in diameter. The surface is smooth, erythematous and often with small superficial erosion at the top [6]. By location, majority of the polyps are found at the esophageal-gastric junction (EGJ), followed by the lower esophagus and the mid esophagus $[5,8]$. A few cases of hyperplastic polyps have been found in the cervical esophagus, usually in association with ectopic gastric mucosa [4,16,17]. Polyps at the EGJ may be located at the end of a prominent inflamed gastric fold of mucosa, also known as "the sentinel fold", seen in reflux esophagitis $[4,6,18]$.

Histologically, esophageal hyperplastic polyps consist of hyperplastic epithelium (foveolartype, squamous, or both) with inflamed stroma of variable proportions [8]. A few polyps could have intestinal metaplasia, which is more commonly found in those that are associated with $\mathrm{BE}[8,11]$. Infrequently, dysplasia could be found in some of the polyps, especially in those that are associated with BE [8]. Malignant transformation has been occasionally reported in gastric and colonic hyperplastic polyps [19-21], but this has not been documented in esophageal hyperplastic polyps.

Abraham et al. studied 30 esophageal hyperplastic polyps from 27 patients by characterizing the clinical, endoscopic and histologic features of both the polyps and the background esophagus [8]. The EGJ was the most common site of the polyps $(67 \%)$, followed by the distal esophagus $(30 \%)$ and the mid-esophagus (3\%). Most (80\%) were composed of predominantly cardiac-type mucosa, predominantly squamous mucosa $(17 \%)$, or an admixture (3\%). Intestinal metaplasia of the polyp was present in only $7 \%$ and low-grade dysplasia in only $3 \%$. Four patients $(15 \%)$ had Barrett's esophagus, three of whom had or developed dysplastic Barrett's mucosa.

The case at hand had two distinct clinical features (GERD and dyspepsia) which were confirmed by endoscopy. A history that is in keeping with GERD in this patient suggests that the 
hyperplastic polyps may have developed by reason of esophageal injury resulting from acid reflux. The atypical endoscopic appearance of the lesions (small nodular lesions as opposed to polypoid lesions) could mean that they were caught at an early stage of development. Interestingly, biopsies of the lesions contained all the characteristic features of fully developed esophageal hyperplastic polyps.

Careful history taking and biopsy of the surrounding non-polypoid mucosa are essential in determining the clinic-pathologic milieu in which esophageal hyperplastic polyps exist [8]. The optimal treatment strategy is still to be defined. While some anecdotal reports showed regression of polyps after a course of anti-secretory therapy such as proton pump inhibitors [5,18], others have not demonstrated regression $[14,18,22]$. The minimum duration of anti-secretory therapy for polyp regression has also not been established. Endoscopic snare polypectomy may be required in those that are symptomatic [23,24]. Endoscopic mucosal resection is recommended in cases that are associated with Barrett's esophagus [4]. We opted for PPI therapy in our patient with the hope that it will take care of all her problems (dyspepsia, GERD and polyps) simultaneously.

\section{Conclusion}

Esophageal hyperplastic polyp is generally rare and the report of the lesion from Nigeria is particularly scarce in the literature. However, the rate of detection and reporting will likely increase as gastrointestinal endoscopy services become more available and accessible in Nigeria.

Contributors: ACJ: case management, literature review, and manuscript writing; MAA: histologic examination, and critical review of manuscript; TSO: case management, and manuscript writing. ACJ will act as the guarantor. All authors approved the final version of the manuscript.

Funding: None; Competing interests: None stated.

\section{References}

1. Choong CK, Meyers BF. Benign esophageal tumors: introduction, incidence, classification, and clinical features. Semin Thorac Cardiovasc Surg. 2003;15:3-8.

2. Watson RR, O'Connor TM, Weisel W. Solid Benign Tumors of the Esophagus. Ann Thorac Surg. 1967;4:8091.

3. Kinney T, Waxman I. Treatment of benign esophageal tumors by endoscopic techniques. Semin Thorac Cardiovasc Surg. 2003;15:27-34.

4. DeCeglie A, Lapertosa G, Blanchi S, Di Muzio M, Picasso M, Filiberti R, et al. Endoscopic mucosal resection of large hyperplastic polyps in 3 patients with Barrett's esophagus. World J Gastroenterol. 2006;12:5699-5704.

5. Tsai SJ, Lin CC, Chang CW, Hung CY, Shieh TY, Wang HY, et al. Benign esophageal lesions: Endoscopic and pathologic features. World J Gastroenterol. 2015;21:1091.

6. Haboubi NY, Geobes K, Shepherd NA, Talbot IC. Polyps of the Oesophagus. In: Haboubi NY, Geobes K, Shepherd NA, Talbot IC, editors. Gastrointestinal Polyps. $1^{\text {st }}$ ed. London: Greenwich Medical Media Limited; 2002. p.111.

7. Buyukasik K, Sevinc MM, Gunduz UR, Ari A, Gurbulak $\mathrm{B}$, Toros AB, et al. Upper gastrointestinal tract polyps: what do we know about them? Asian Pac J Cancer Prev. 2015;16:2999-3001.

8. Abraham SC, Singh VK, Yardley JH, Wu TT. Hyperplastic polyps of the esophagus and esophagogastric junction: histologic and clinicopathologic findings. Am J Surg Pathol. 2001;25:1180-1187.

9. Umar AK, Ahmed S, Almustapha L, Aliyu H, Abdullahi $\mathrm{S}$, Yates S, et al. Hyperplastic polyps of the esophagus and esophagogastric junction with esophageal constriction a case report. Pathology. 2014;46:S81.

10. Jain R, Chetty R. Gastric Hyperplastic Polyps: A Review. Dig Dis Sci. 2009;54:1839-1846.

11. Long KB, Odze RD. Gastroesophageal Junction Hyperplastic (Inflammatory) Polyps. Am J Surg Pathol. 2011;35:1038-1044.

12. Rabin MS, Bremner CG, Botha JR. The reflux gastroesophageal polyp. Am J Gastroenterol. 1980;73:451-455.

13. Zitsman JL, Schullinger JN, Berdon WE. Inflammatory esophagogastric polyps: resolution following antireflux surgery. J Pediatr Surg. 1988;23:1016-1017.

14. Diaconescu S, Miron I, Gimiga N, Olaru C, Ioniuc I, Ciongradi I, et al. Unusual Endoscopic Findings in Children. Medicine. 2016;95:e2539.

15. Grynspan D, Lukacik M, Madani S, Poulik J. Two hyperplastic esophagogastric polyps in a child with neurofibromatosis Type 1 (NF-1). Pediatr Dev Pathol. 2008;11:235-238.

16. Alagozlu H, Ergun M, Cindoruk M, Unal S, Dumlu S, Poyraz A, et al. The rare presentations of a large polyp and an esophageal carcinoma in heterotropic gastric mucosa: a case series. J Med Case Rep. 2007;1:127. 
17. Oguma J, Ozawa S, Omori T, Kitagawa Y, Saikawa Y, Mikami S, et al. EMR of a hyperplastic polyp arising in ectopic gastric mucosa in the cervical esophagus: case report. Gastrointest Endosc. 2005;61:335-338.

18. Bishop PR, Nowicki MJ, Subramony C, Parker PH. The inflammatory polyp-fold complex in children. J Clin Gastroenterol. 2002;34:229-232.

19. Daibo M, Itabashi M, Hirota T. Malignant transformation of gastric hyperplastic polyps. Am J Gastroenterol. 1987;82:1016-1025.

20. Morimoto LM, Newcomb PA, Ulrich CM, Bostick RM, Lais CJ, Potter JD. Risk factors for hyperplastic and adenomatous polyps: evidence for malignant potential? Cancer Epidemiol Biomarkers Prev. 2002;11:10121018 .
21. Jørgensen H, Mogensen AM, Svendsen LB. Hyperplastic polyposis of the large bowel. Three cases and a review of the literature. Scand J Gastroenterol. 1996;31:825-830.

22. Septer S, Cuffari C, Attard TM. Esophageal polyps in pediatric patients undergoing routine diagnostic upper gastrointestinal endoscopy: a multicenter study. Dis Esophagus. 2014;27:24-29.

23. Moriyama T, Matsumoto T, Jo Y, Iwai K, Yao T, Iida $\mathrm{M}$, et al. Pseudomalignant erosion in an inflammatory polyp at esophagocardial junction. Gastrointest Endosc. 2003;57:987-989.

24. Glassman M, Bostwick HE, Godine L, Newman LJ. Endoscopic removal of inflammatory esophagogastric polyps in children. J Pediatr Gastroenterol Nutr. 1991;13:110-114. 